\title{
Institutional Methods Used for Organizational Processes within Public Relations in Light of Standards for Developing Institutional Work
}

\author{
Maha Mustafa Omer Abdalaziz
}

\begin{abstract}
The study aimed to identify the institutional methods used for organizational processes within the Public Relations Department in light of the standards for developing institutional work. The sample of the study consisted of (104) members of a number of government institutions, as this study falls within the descriptive research that depends on the survey method by the questionnaire, and among the most important results of the study: The study proved that there are institutional methods used in the organizational processes of public relations and that they are interconnected and integrated to the end In order to achieve the objectives set for the institutional development process in the institutions in which they work, which reflects sustainability, improvement and facing external challenges, we find that the majority of the sample respondents consider that the institutional methods of the organizational processes of public relations are the backbone of institutional and organizational development, where the percentage of those who approve was strongly (19.2\%) and approved by a percentage of (31.7\%) of the total sample surveyed, provided that the organizational processes and methods used within public relations to develop them for institutional work in the short and long term The study also showed that the organizational processes for public relations and their standards in the development of institutional work within institutions are nothing but a type of administrative development that includes Internal job performance and proper planning, where the results were interpreted by the majority of the respondents sample $N$ agree (39.4\%) and strongly agree (19.2\%) of the existence of a work environment that uses best administrative practices represented in training and development plans in light of the information revolution for their institutions to develop in line with the career path and work needs. The study also recommended: It is necessary to pay attention to the processes of comprehensive institutional building because it is the nucleus from which the organizational processes used for public relations are based, through review, evaluation and addressing the deficiencies of development plans for institutional work that suffer from weaknesses and deficiencies due to the lack of specialized and qualified competencies to develop and evaluate those plans. In addition to the existence of another body that is concerned with the continuous evaluation and accountability.
\end{abstract}

Key words: institutional methods, organizational processes, public relations, standards, development of institutional work.

Revised Manuscript Received on December 05, 2020.

* Correspondence Author

Dr. Maha Mustafa Omer Abdalaziz*, College of Mass Communication and Public Relations / University of Fujairah / Emirate of Fujairah / United Arab Emirates / maha@uof.ac.ae Sciences Publication (BEIESP). This is an open access article under the CC BY-NC-ND license (http://creativecommons.org/licenses/by-nc-nd/4.0/)
(C) The Authors. Published by Blue Eyes Intelligence Engineering and

\section{INTRODUCTION}

The institutional methods of organizational processes in public relations management constitute one of the basic pillars through which internal administrative interaction takes place; Which depends on the effectiveness of institutional communication within the institution. Therefore, the institutional methods of organizational processes are among the most important methods and channels that the Public Relations Department follows in developing its institutional work. Implicitly, it is the sum total of communication and administrative processes that organize work within the organization and create an atmosphere of understanding, cooperation and coordination between the various departments and work to develop the institution on the one hand and communicate with its audience on the other hand. As the main nerve for the transfer and organization of data and information and the dissemination of administrative systems that help allow in the process of rational and sound decision-making, and if institutional methods are an imperative necessity in all stages of institutional work, which we can call the conceptual redesign, which includes the standards and strategy of public relations management in this related administrative context As networks of organizational processes evolve; By means of corporate-organizational communication dialogue that has proven effective in improving communication and facilitating two-way communication; Which led to the reformulation of this institutional methods in a way that helps to crystallize the institutional methods used in managing public relations within institutions, attitudes, trends and solutions to problems mainly derived from attitudes and practices in the development of institutional work; The traditional organizational processes are no longer able to effect this change; Rather, it has become unable to deal with the direct and effective impact of the Public Relations Department, especially with regard to the method of developing institutional work. Modern public relations have a strategic management culture with an integrated communication activity to develop institutional work in its various fields. And spreading awareness of the basic elements for developing institutional work among all employees, as it is the institutional pillar of the organizational operations strategy that enhances the capabilities of public relations practitioners in institutions with technological developments in their various organizational processes;

Published By:

Blue Eyes Intelligence Engineering

\& Sciences Publication

DOI:10.35940/ijmh.D1196.125420

Journal Website: www.ijmh.org

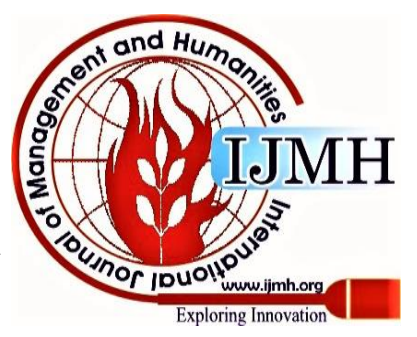


And its role in increasing the effectiveness of modern institutional methods of public relations and its standards for the development of institutional work, because they are the source of their formation and a factor in their dissemination and expression.

\section{PROBLEM}

The problem of this study is determined in the role of public relations in knowing the organizational processes and their methods in developing institutional work. And the administrative organizational barriers that they cause at the different organizational levels, and what is the institutional method used for public relations to solve the problems that may face organizational processes in their methods of communication between management and workers, or vice versa, or between workers at the same level within the organization, through the standards on which are found methods used as one One of the methods of effective communication to overcome obstacles that hinder the process of effective organizational processes and its importance for public relations within organizations with different activities. Therefore, this current study complements the efforts shown in previous studies. Given the importance of the methods used in public relations for institutional development.

\section{METHODOLOGY}

In this study, the researcher pursued descriptive survey research aimed at photographing and evaluating the characteristics of a certain group of the problem of institutional self-evaluation to develop governmental institutional work and the organizational processes followed within it. With the aim of obtaining full information about it; Within the framework of the survey method, the researcher surveyed the general sample of a group of government institutions. the study was applied to an intended sample from among the non-probability samples, for public relations workers in particular, and workers in government institutions in general, and accordingly the study relied on a sample of (104) singles.

\section{LITERATURE REVIEW}

\section{Organizational processes in public relations}

First: The concept of organizational processes in public relations:

The use of the term organizational processes is related in a deeper way to the behavior, structure, climate and organizational culture of institutions, and some believe that the use of the term organizational processes is nothing but organizational development as an extension of the behavioral schools that supported the efforts of the modern school of thought in the new view of the individual human, and focused mainly on the human side and considered it as the basis Production process, as definitions focus on the importance of the human dimension in organizational processes, and organizational processes are defined as including reference to different approaches. Behavioral sciences have directed management organizations towards openness and honesty. Where Redding and Sanborn define the organizational processes as "changing the scheme in order to transform the organization from an effective organization to a more efficient one," and we mean changing the scheme is a deliberate change and not an end in itself; Rather, it is a tool and a method for achieving the goal of "not just for change" and "Zelko and Dance" define that organizational processes are "an interdependent system that includes internal and external communication and relates to the communication skills of a business organization" (1)

As he defines the organizational processes in public relations, it is nothing but a "long-term process aimed at the ability of the institution to solve its problems and renew itself by achieving comprehensive development in the prevailing climate and focusing on increasing the efficiency of the organization." As for Burns' definition of organizational processes in public relations as "creating harmony between the environment, processes, strategies, and individuals in the organization, and between culture and the development of creative and organizational solutions; thus it is a means of developing the organization's ability to renew itself." We note from the foregoing that organizational processes are a natural health phenomenon in the life of administrative institutions and have great importance in increasing the efficiency and effectiveness of institutional performance, especially in this era that requires complete modernization in all fields, because comprehensive development depends on the existence of effective administrative institutions based on research, study and analysis, to develop All data of the department, especially in its organizational and modernization aspect, in order to raise levels of institutional performance, which leads to creating the appropriate organizational climate to increase performance and professional affiliation. Bearing in mind that the main role of the organizational processes of communication is the coordination role that coordinates between personal goals and the goals of the organization of the company on the one hand, and between activities that can generate problems on the other hand (2), and accordingly, organizational processes in public relations are a continuous process. It aims to increase the qualifications and skills of employees, improve production technology, management models, forms of organizational communication and public relations, in order to increase the capabilities of the institution to keep pace with the development of competitors necessary for the continuation of the administrative process. (3)

Second: Factors of organizational processes in public relations:

Institutions face many changes and developments in their work environment, due to the fact that they are exposed to many pressures imposed by events, changes and developments in their work environment. So the factors of organizational processes in public relations can be divided into external and internal:

1. They are represented by the external factors:

- Variables related to market conditions and audience needs.

- Variables related to technology use.

- Variables related to the political and legislative environment.

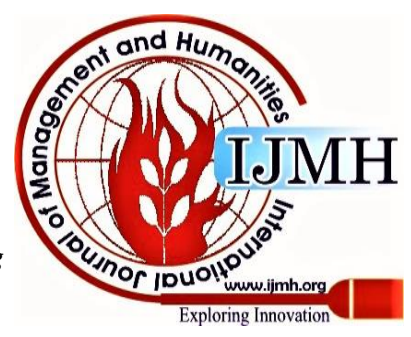


This means that the organizational processes resulting from the change of the external environment aims to harmonize between the institution and its external environment and how to control this environment that helps to develop institutional work and since public relations is a tool that links between its external environment because it is a means of defining the external environment with the positive role that the organization plays in service.

His work, which means that public relations has a role to play in positively influencing public opinion and interest groups, in order to generate this consensus. (4)

\section{They are represented in the internal factors:}

The need for change or organizational processes arises when new developments occur in the internal work environment and the capabilities and goals of the organization or when the organization faces subjective issues within the organization, which makes the current organization insufficient to deal with the changes that occur in the environment, necessitating the need to establish organizational processes in the organization. Here, the role of public relations appears in preparing the internal environment to accept this change by communicating with influential groups within the organization to explain the justifications and causes of change, so that it has a positive impact on people.

From the above, it can be said that the organizational processes in public relations have other factors that push public relations to make changes according to its organizational and administrative standards to develop institutional work, including: (5)

1)Development of the capacity for innovation: Organizational processes in public relations always require efforts to keep up with them, whether it is a positive treatment of adaptation or a negative treatment of rejection, and both types of interaction require finding innovative means, tools and methods in methods, form and content.

2) Stir up the desire for development, improvement and upgrading: Public Relations works to develop work in comprehensive and integrated development that is based on the application of new production methods based on new technologies.

3) Compatibility with life variables: Organizational processes aim to increase the ability to adapt and adapt to the variables of life, and what institutions face in terms of different circumstances and fixed situations and an environment in which many factors, ideas, trends, strengths and interests interact.

4) Raising the level of performance: Organizational processes aim to achieve the highest levels of executive performance and operational practice through:

- Discovering weaknesses and gaps that lead to decreased performance and the possibility of remedying them.

- Knowing and affirming strengths such as: motivational processes, improving the work environment, increasing the desire for positive interaction with workers, and loyalty and commitment to work.

\section{Institutional characteristics of organizational processes} in public relations:

Organizational processes in public relations are characterized by certain characteristics that distinguish them from other processes of change, including inclusiveness, continuity and participation through concern for the workforce, internal organization, work methods, and applicable laws. According to the classification of the standard or set of standards, it helps in analyzing the organization and leading the comparative study that is compared with each other, in addition to determining the factors that lead to this similarity or difference on the basis of different criteria or simulations such as: the size of the institution, its objectives, functions, technology, the organizational structure and the main benefactor of organization and organizational power; Among the most important characteristics of organizational

processes in public relations are: (6)

- Completeness: means completeness and interest in the human elements that work, internal organization, work methods, laws and regulations applied in the organization.

- Continuity: means continuing to improve the work environment and the general climate of the organization.

- Participation: means the participation of all members of the organization in the organizational processes because they are the main source of the driving force for development.

\section{Institutional methods of organizational processes in} public relations:

There are four types of institutional methods for the organizational processes of public relations management according to their usefulness and importance in relation to institutional analysis, namely: (7)

1. Institutional style of the organizational process within public relations according to the first beneficiary of organizational activities: These institutional methods are classified into four types as follows: (8)

a. Shared institutional: The main beneficiaries of organizational activities are the members. Examples of these organizations: trade unions, political parties, professional bodies ...

1. Labor systems: the first beneficiaries are the owners of factories, banks and insurance companies that seek for profit.

2. Service regulations: the main beneficiaries are customers, such as hospitals, care institutions, and schools.

3. Public interest institutions: the public will be the first to benefit from the institution's activities. Usually, examples include military, police and civil defense organizations. These organizations operate under public scrutiny, so they must work to increase their effectiveness in order to meet the public's needs. According to this standardization, it is difficult to determine the primary beneficiary of the activities performed by the enterprise.

Published By:

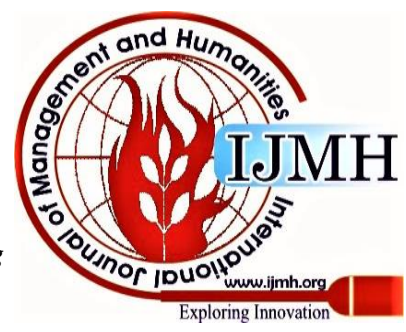


b. Institutional approach to the organizational process in technology-based public relations:

- These institutional trends are classified as follows according to the technology used. Organizations on the basis of the degree of complexity of the technology used in the following three types:

- Establishments that use simple technology: production is done individually and in small quantities.

- Institutions that use large production processes: We see that such organizations rely on assembly lines to produce large quantities of units such as televisions and cars.

- Institutions that use very complex production processes: In these organizations, the production processes are continuous, such as organizations working in the petroleum refining industry. (9)

c. Institutional style of the organizational process of the institution according to its functions: It is the organization of business by structural analysis of the job, which is called the requirements of the job, and the requirements are considered to be compatibility, achieving the goal, integration, control or reduction of tensions, so the institution as a social group must meet these requirements and make sure to study them if it will perform its duties.

\section{Institutional work development}

\section{First: the concept of institutional work:}

The term " institutional work " is considered one of the administrative and organizational terms that have taken a mediator in recent times, and it has become frequent from time to time and is called by many leaders and workers on the grounds that it is the savior from the administrative deterioration, financial corruption and organizational defects that our institutions are experiencing, but what is the institutional work? What is meant by this term? What made me ask such a question and dealt with such a topic is what I have noticed from the frequent calls for some leaders and the repeated repetition of the concept of institutional work, and in order for the concept of institutional work to become clear, we can return to the most prominent modern and traditional managerial theories of thought, so that the discussion is objective and valuable, and therefore we can say That the experiences of executives of successful enterprises. (10) where the idea of institutional work is based on the fact that there are fixed elements in social life - institutions - that have a profound influence on the ideas, feelings and behavior of individual and collective actors. He describes institutions as consisting of "cultured, cognitive, normative and organizational elements that provide Stability and meaning for social life (11) where it is in terms represented in symbolic, administrative, communicative and organizational systems, operating at multi-disciplinary levels. Where the focus is on the organization and human perception in defining institutions with "common rules and meanings" that define social relations, to explain behavior Others, "the point of view of administrative departments that are based on the development of the institutional work of institutions and their role in the perception of the concepts of institutional work. (12)

Accordingly, the concept of institutional work is to describe institutions as: "the humanely established restrictions that the structure of political, economic and social interaction. As such, it consists of both formal restrictions (penalties, prohibitions, customs, traditions, and codes of conduct) and official rules (constitutions, laws and property rights). (13) and accordingly, we point out that the concept of institutional work is the patterns of chain reaction supported by specific mechanisms of control; and that the articulation of the basic elements for the study of institutional work and organizational work is nothing but providing a strong theoretical basis for the concept of institutional work. The institutional work we seek is characterized by a group of Specifications and characteristics that make it a distinguished work, and the most important of these characteristics are the following: (14)

1. Institutional work guarantees the stability and continuity of work, maintains the accumulation of expertise, experience and information, and is not affected by the change of leadership, as it is managed by specialized competencies of high professional performance.

2. Institutional work ensures that the leader or leadership is not uniquely taking the fateful decisions related to the institution, as there is more reliance on specialized bodies that provide studies and research assistance.

3. Institutional work maintains the administrative and financial stability of the institution, by following a set of work systems (policies, rules and procedures) that work on the goals and means in line with the vision of the institution

4. Institutional work ensures that all its employees are committed to a set of values and principles around which their performance, behavior, and employment and human relations are centered.

5. Institutional work ensures that it supports the institution with the best human resources, by following an advanced policy of selection and recruitment, and a systematic approach to qualification and training in order to achieve continuous professional development.

6. Institutional work confirms the organization's readiness to provide alternative leadership in times of necessity and emergency, and the institution's entry into a crisis of any kind or in an emergency situation that requires change and alteration.

\section{Second: Standards for developing institutional work}

We find one of the most important pillars of the development of institutional work in general and its role in developing the institutional building and its basic components; Which are the strong pillars, the more the institutional structure is strong, the public relations is a department with communicative and administrative activity that accurately supports the institutional structures; Which are as follows: (15)

1) Organizational structure: every organization has an

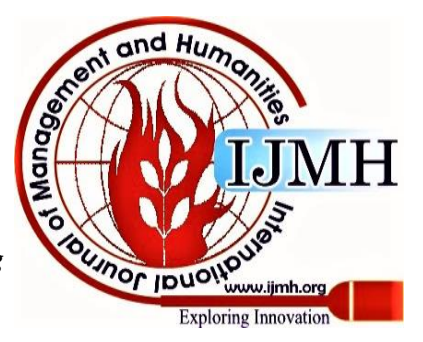


organizational structure that clarifies the division of activities, works, duties, divisions and departments, and the process of organizational building requires defining the objectives of the organization and then defining the various aspects of the activities in the required work, defining the required processes in each activity and grouping them into administrative units and work capabilities; Where the organizational structure is considered a major tool that helps the administration to organize and coordinate the efforts of workers to reach pre-agreed goals. (16)

2) Institutional Efficiency: it is defined as the effectiveness and efficiency of the institution in using its available resources to achieve its objectives in an optimal manner. There is a difference between Effectiveness and Efficiency. Efficiency is defined as doing the right things. As for efficiency, it is defined as doing things well. All of these meanings are intended to define institutional competence. Institutional efficiency includes: effectiveness of planning, effectiveness of implementation, control and follow-up, and effectiveness of communications. (17)

3) Effective leadership: it refers to the leadership's ability to create distant visions, formulate goals, develop strategies, and achieve cooperation for action. Effective leadership is what formulates visions for the future, taking into account the rational strategy towards those visions while ensuring the support of the main power centers to work with those around them. Therefore, it focuses on three main processes: defining the direction and vision, mobilizing forces under it, and motivating and motivating in order to achieve that vision. With clarity in the priorities and operational plans, and the continuous development of the cadres working in the institution. (18)

4) Public Relations Department: The Public Relations Department is a leadership management for employees to achieve institutional goals by creating conditions that enable the organization's employees to perform, then evaluating performance to determine the training and development needs of the institutional work. (19)

5) Institutional systems and methods in institutional work: It is the set of institutional policies, rules and methods that govern the activity of the institution to achieve its standards, which consist of the following: (20)

1) Policies: They are the comprehensive regulations, decisions and provisions adopted by the higher management in the organization, and they are relied upon in the institutional rules, methods and work procedures.

2) Institutional methods (Rules \& methods): they are established foundations and principles related to a specific activity in how to act in applying procedures. Where the institutional rules and methods can develop with the development of the institution without any change in the policies, but they are inevitably affected by the development of these policies and are inevitably reflected in the procedures.

3) Steps: It is the series of operations that make up the procedure, with identifying the work and the tools used to implement it, including models and devices. (21)

Third: organizational processes and standards for developing institutional work:
Interest in organizational processes has become a concern of all organizations as it is the point of strength and distinction in the information age. The organizational processes in recent years have been characterized by rapid developments and direct impacts of the digital revolution on the human lifestyle at the economic, social and cultural levels, which make development in all fields closely linked to the extent of the human being's ability to cope with these transformations and control them in order to exploit the available and renewable capabilities in this era and the ability to create Effective communication from various digital means.

One of the most important organizational processes and standards for developing institutional work: (22)

1. Invention of new digital means of communication that changed the traditional functions of the old means and created new jobs for them.

2. The volume of available information has increased the opportunities for obtaining new digital communication technology due to the current developments in the process of sending and receiving information.

3. The continuous development of digital networks by ensuring their ease of use and development of their content.

4. The digital communication system is characterized by the activity and strength that makes institutional communication a high-quality integrated unit.

Organizational processes have become an important criterion in the development of institutional work or what we can call information systems that have fundamentally contributed to the success or failure of any institution. Which is used as a tool for coordination and support of the administrative process and decision-making on the one hand, and as a communication tool within the organization and with the surrounding environment on the other hand. The corporation, in front of the processes of expansion, geographical spread, productive diversification, marketing and financing operations, the need for human resources and other activities, finds itself in need to establish an appropriate structure for these activities in a manner that ensures the flow of organizational processes from the various units, analyzing this communication information and using it in the development of institutional work in general and in the development of Its administrative performance in particular. Administrative activity in business enterprises has a very close relationship with information communication systems, which gives a strategic character to information systems as a tool capable of creating and consolidating competitiveness and achieving goals. (23)

Institutional methods used in the organizational processes of public relations in light of standards for developing institutional work

There have been many institutional methods within the Public Relations Department for the standards of developing institutional work on which the organizational processes are based, accordingly according to which an ideal type or style that is suitable for all institutions is determined and whose optimal approach may differ according to the institution's objectives,

Blue Eyes Intelligence Engineering

\& Sciences Publication

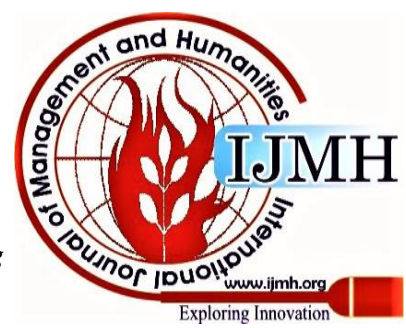




\section{Institutional Methods Used for Organizational Processes within Public Relations in Light of Standards for Developing Institutional Work}

the nature of its activity and the quality of its work, as well as according to its own circumstances in terms of its size, duration of life and location of work

The extent of its specialization, the type of technology it uses, the human capabilities it needs, as well as the environmental conditions surrounding it. Accordingly, we find one of the most widely used institutional methods: (24)

1. Digital methods: It is a method based on the compilation of a number of performances in certain tasks under the leadership of a specific chief depending on the size of the manpower.

2. Timing methods: where this organization is suitable at the lower administrative levels to operate the institution around the clock, so employees are distributed in similar periods in what is known as this organization (shifts).

3. Occupational styles: This organization is based on the principle of specific specialization in work by dividing, grouping and distributing activities in the form of specific jobs such as a planning or financing function.

4. Institutional methods based on the type of beneficiaries of the institution's services and dealing with them: This method is resorted to if there are special considerations that necessitate the difference in the type, nature and conditions of dealing with the community benefiting from the institution's services or classes of its clients. (25)

From the above, it can be said that one of the most important signs of developing institutional work is the existence of a strategic vision for the work of the institution through which it guarantees the organization's regular and continuous progress in the long term. What was previously known as the mentality of individual work, continuous follow-up of employees, the loss of production sources and the reluctance to make decisions with growth The slow pace of the organization is the basis for the selection of modern executive leadership for strategic pioneering work. Formulating institutional methods for organizational processes within public relations to develop institutional work is one of the most important features of the strategic work that modern professional institutions seek, and that having a clear work vision within institutions will achieve great importance for the organization for different business levels, which confirms its long-term continuation. According to the principles, values and goals for which it was established. (26)

Studies have shown that the institutional methods used for organizational processes within public relations in the development of institutional work are related to the extent of the commitment of the local community to provide all forms of support to the institution, so the participation of the local community in any strategy to spread reforms in the institution is a good thing, and therefore the lack of participation of the local community in the programs or activities of the institution And its policies constitute an obstacle to the institution's transformation towards developing the institutional methods used in the organizational processes of public relations for institutional work.

Accordingly, the public relations system and the development of institutional methods are affected by existing policies and work systems, as they either hinder or support work. In the institution, policies and work systems are imposed on it from the top in many cases. For example, the conflict between policies that are imposed on The institution to achieve quantitative goals (implementing a number of programs independently of the extent of its performance determining the number of training courses for the institution's employees ... etc.), and between the internal policies of the institution that focus on achieving high outputs. Institutional work will impede the transformation and the success of performance and work in the organization. In addition to this, there is also the multiplicity of the supervisory authorities over the institution and the use of these bodies for traditional work systems that do not coincide with the aspirations of the institution towards development, as they constitute an obstacle to the institution's transformation to development. From the perspective of the public relations system in the development of institutional work, these entities are considered "suppliers" meaning that they contribute to their supervisory services. In the institution's system, and therefore they are part of the system they are influential in it. The problem of the institution is that it does not have the freedom to choose its suppliers, especially the supervisory authorities. Therefore, the successive developments in digital communications have changed what can be called the nature of the public sphere in which individuals live, as they have the ability to express their views on public policy issues. These developments were reflected in the field of public relations practice as an administrative and communication function in developing the institutional work style. It has become imperative for public relations practitioners to rethink their communication strategies in light of recent developments, especially communication, the most important of which is the use of Internet networks. Thus, it can help in the strategy for its administrative processes that proceed through this technological development that the Public Relations Department can take in developing institutional work namely:

1. The institutional direction of public relations and the style of organizational processes according to the strategies at the level of the institution: It focuses on describing the general direction of the institution in terms of growth and institutional methods, managing multiple activities, the relationship between the institution and interest groups, and the entrances that the institution can use to increase continuous development. The strategy of the institution may take one Some of the forms, including what is known as the stability strategy, or what is sometimes called the limited growth strategy, as it works in the relatively internal stability industry and in an external environment that is not turbulent, and in accordance with this strategy, the Corporation seeks to continue its current approach by focusing on what it offers in order to enhance and improve its competitive environment.

2. The institutional direction of public relations and its approach to the organizational process in reshaping and implementing institutional work: It is a strategic choice through which the strategy that best achieves the availability of the objectives of the organization from among a number of alternatives is chosen, which may be at the general level, at the business level, or at the job level.

Published By:

Blue Eyes Intelligence Engineering

\& Sciences Publication

DOI:10.35940/ijmh.D1196.125420

Journal Website: www.ijmh.org

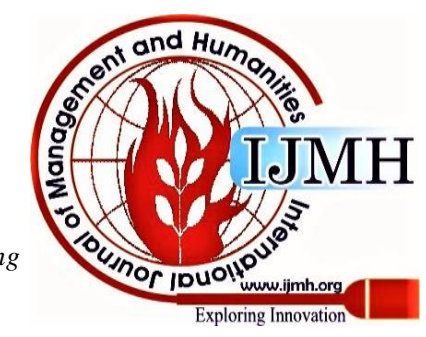


3. The institutional direction of the organizational process and public relations standards in developing institutional work: It is a set of descriptive elements that contain information related to monitoring the variables that take place on information and communication and how to manage them in order to ensure coherence and consistency that helps in evaluating development plans and programs to reach the desired goals.

4. The institutional direction of public relations strategies in organizational processes and the development of institutional work: This strategy is intended to develop public relations interests of the institution through its functions, institutional methods and tasks in relation to serving its public in a way that harnesses information technologies, which supports the institutional procedural systems and facilitates the speed of response and the application of institutional decentralization And knowledge building due to the electronic work mechanism, which is subject to constant developments and developments.

5. The institutional methods used and the method of public relations through defining the roles and advantages of developing the institutional work: by which we mean the grouping of all activities, programs, and digital, interactive and reciprocal communication services in the context of the institutional framework; To achieve the status of permanent organizational processes in the public to secure all service needs. In addition to achieving the speed and effectiveness of the connection, coordination and performance between all departments and departments separately.

\section{DISCUSS THE RESEARCH FINDINGS}

The researcher approved the analysis of these data through the use of the Statistical Package Program in the Social Sciences (SPSS), using statistical methods of frequencies, percentages, arithmetic mean and standard deviation according to the variables (gender / age / academic qualification / years of experience). Public relations in various institutions (governmental and private) and it was as follows:

Table No. (1) Distribution of the sample members by gende

\begin{tabular}{|c|c|c|}
\hline Gender & Average & Percentage \\
\hline Male & 75 & $72.1 \%$ \\
\hline Female & 29 & $27.8 \%$ \\
\hline Total & $\mathbf{1 0 4}$ & $\mathbf{1 0 0 \%}$ \\
\hline
\end{tabular}

Table No. (1) becomes clear to us that the number of males in the researched sample reached $(72.11 \%)$, while the total number of females reached $(27.8 \%)$ of the total sample studied.

Table No. (2) Distribution of sample individuals according to age

\begin{tabular}{|c|c|c|}
\hline Age & Average & Percentage \\
\hline UNDER 25 YEARS OLD & 12 & $11.5 \%$ \\
\hline $25-35$ & 28 & $26.9 \%$ \\
\hline $36-45$ & 34 & $32.6 \%$ \\
\hline OVER 45 YEARS OLD & 30 & $29.8 \%$ \\
\hline
\end{tabular}

\begin{tabular}{|c|c|c|}
\hline Age & Average & Percentage \\
\hline Total & 104 & $100 \%$ \\
\hline
\end{tabular}

Table No. (2) shows the distribution of the sample members according to age, where we find that $(11.5 \%)$ of the total sample respondents are less than 25 years old, (26.9\%) of the sample respondents are between 25-35 years old, (32.6\%) of the respondents. The respondents of the sample ranged from 36 to 45 years old, $(29.8 \%)$ of the sample respondents were over 45 years old.

Table No. (3) Distribution of the sample members according to academic qualification

\begin{tabular}{|c|c|c|}
\hline \multicolumn{1}{|c|}{ Academic qualification } & Average & Percentage \\
\hline Diploma & 48 & $46.1 \%$ \\
\hline Bachelor & 45 & $43.2 \%$ \\
\hline Above university & 11 & $10.5 \%$ \\
\hline Total & $\mathbf{1 0 4}$ & $\mathbf{1 0 0 \%}$ \\
\hline
\end{tabular}

Table No. (3) is the distribution of the sample members according to academic qualification, we find that the sample respondents hold a diploma, (46.1\%), (43.2) of the sample respondents have a bachelor's degree, while (10.5\%) of the sample respondents hold postgraduate studies.

Table No. (4) Distribution of the sample according to years of experience

\begin{tabular}{|c|c|c|}
\hline years of experience & Average & Percentage \\
\hline Less than 5 years & 10 & $9.6 \%$ \\
\hline 5 - 10 years & 25 & $24 \%$ \\
\hline 10 - 12 years old & 33 & $31.7 \%$ \\
\hline 12 - 15 years and over & 36 & $34.6 \%$ \\
\hline Total & 104 & $100 \%$ \\
\hline
\end{tabular}

Table No. (4) above concerning the distribution of the sample members according to years of experience, we find that $(9.6 \%)$ of the respondents have practical experience of less than 5 years, (24\%) of the sample respondents have ryears of experience ranging between (5-10) Years, (31.7\%) of the sample respondents have years of experience ranging between (10-12), while (34.6\%) of the respondents have years of experience of 12-15 years and more.

Table No. (5) Distribution of sample individuals according to the institutional methods used in the organizational processes of public relations and their role in institutional development

\begin{tabular}{|c|c|c|}
\hline Statements & Average & Percentage \\
\hline STRONGLY AGREE & 20 & $19.2 \%$ \\
\hline STRONGLY & 33 & $31.7 \%$ \\
\hline NOT AGREE & 17 & $16.3 \%$ \\
\hline STRONGLY DISAGREE & 21 & $20.1 \%$ \\
\hline Total & $\mathbf{1 0 4}$ & $\mathbf{1 0 0 \%}$ \\
\hline
\end{tabular}

Published By:

Blue Eyes Intelligence Engineering

\& Sciences Publication

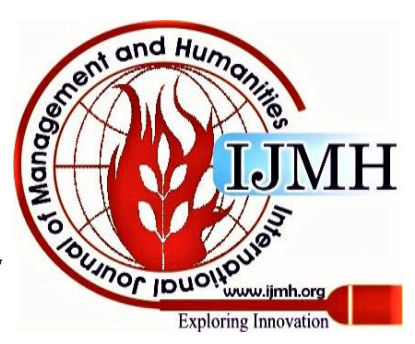


Institutional Methods Used for Organizational Processes within Public Relations in Light of Standards for Developing Institutional Work

Table No. (5) for the distribution of individuals in the sample according to the institutional methods used in the organizational processes of public relations and their role in institutional development. We find that the majority of the respondents of the sample consider that the institutional methods of the organizational processes of public relations are the backbone of institutional and organizational development, where the percentage of those who agree is strongly (19.2\%) and those who agree with $(31.7 \%)$ of the total sample surveyed, but there is a percentage $(16.3 \%)$ who were neutral in explaining whether there is a role for organizational processes as methods that can be used to develop institutional work. As for the non-conformists, their percentage (20.1\%) stated that the organizational processes and methods used within public relations to develop them for institutional work do not represent this clear role, but as a mediator in communicating the organizational operations of the organization as a whole and for public relations as a special administration.

Table No. (6) Distribution of the sample members according to the organizational processes mechanisms used in the Public Relations Department in developing the institutional work

\begin{tabular}{|c|c|c|}
\hline Statements & Average & Percentage \\
\hline Strongly Agree & 19 & $18.2 \%$ \\
\hline Strongly & 44 & $42.3 \%$ \\
\hline not agree & 28 & $8 \%$ \\
\hline Strongly Disagree & 13 & $26.9 \%$ \\
\hline Total & $\mathbf{1 0 4}$ & $\mathbf{1 0 0} \%$ \\
\hline
\end{tabular}

Table No. (6) shows the distribution of the sample members according to the mechanisms of organizational processes and the institutional methods used in public relations to develop the institutional work in government institutions, as the results indicated that the majority of the sample respondents consider that there are mechanisms that have helped the Public Relations Department in developing its institutional knowledge through organizational processes This is represented in the development of systems, structures and strategies, which leads to good employment and investment of human resources, as the percentage of respondents was strongly $(18.2 \%)$ of the total sample of the respondent, and (42.3\%) of the sample agreed on the existence of mechanisms for organizational processes in solving problems and then strengthening Abilities to handle business requirements. However, there were neutral answers that did not clarify this by (8\%), while the percentage of those who disagreed was (26.9\%) due to the lack of clear mechanisms for the organizational processes used in public relations in their institutions.

Table No. (7) The distribution of the sample members

according to the basic pillars of the organizational processes of public relations and the extent of achieving positive interaction for the development of institutional work

\begin{tabular}{|c|c|c|}
\hline Statements & Average & Percentage \\
\hline Strongly Agree & 10 & $9.6 \%$ \\
\hline Strongly & 45 & $43.2 \%$ \\
\hline
\end{tabular}

\begin{tabular}{|c|c|c|}
\hline Statements & Average & Percentage \\
\hline not agree & 27 & $25.9 \%$ \\
\hline Strongly Disagree & 22 & $21.1 \%$ \\
\hline Total & $\mathbf{1 0 4}$ & $\mathbf{1 0 0 \%}$ \\
\hline
\end{tabular}

Table No. (7) shows the distribution of the sample members according to the basic pillars of the organizational processes of public relations and the extent of achieving positive interaction for the development of institutional work. The results were interpreted by the fact that the majority of the sample respondents consider that developing the organizational structure of their institutions is what guarantees the activation of communication and communication channels within them and the participation of all in decision-making. Therefore, there is an effective role in achieving interaction within the institution, as the percentage of approval reached (43.2\%) of the total sample of respondents. As for the percentage of non-conformists, their percentage was (21.1\%). As for the answers of the neutral, their percentage was (16.3\%) of the total sample surveyed.

Table No. (8): The distribution of the sample members according to the work environment that uses the best existing administrative practices in light of the standards of the organizational operations of public relations studied. And its reflection in directing behavior within its institutions

\begin{tabular}{|c|c|c|}
\hline Statements & Average & Percentage \\
\hline Strongly Agree & 20 & $19.6 \%$ \\
\hline Strongly & 41 & $39.4 \%$ \\
\hline not agree & 13 & $12.5 \%$ \\
\hline Strongly Disagree & 30 & $28.8 \%$ \\
\hline Total & $\mathbf{1 0 4}$ & $\mathbf{1 0 0 \%}$ \\
\hline
\end{tabular}

Table No. (8) shows the distribution of the sample members according to the work environment that uses the existing best administrative practices in light of the standards of the organizational operations of public relations studied. And its reflection in directing the behavior within its institutions, where the results were explained by the fact that the majority of the respondents agree (39.4\%) and strongly agree (19.2\%) to the existence of a work environment that uses the best administrative practices represented in the training and development plans in light of the information revolution for their institutions to develop in line with the path As for the sample of respondents who do not agree with a rate of (28.8\%), work practices based on organizational processes still suffer from great weakness in terms of the quality of the programs provided. In addition, the offered programs are limited and scarce and the consequent deficiency in developing knowledge and skills The employee, and training plans and strategies are largely absent; Making the desired results of guiding the behavior that is stagnant. While the percentage of the neutral sample was $(4.8 \%)$ of the total sample.

Published By:

Blue Eyes Intelligence Engineering

\& Sciences Publication

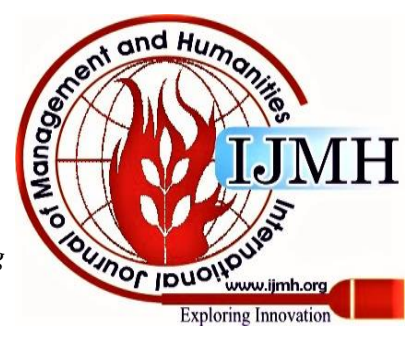




\section{RESULT AND DISCUSSION}

1) The study proved that there are institutional methods used in the organizational processes of public relations and that they are interdependent and integrated, so that they ultimately lead to achieving the goals set for the institutional development process in the institutions in which they work, reflecting sustainability. And improvement and facing external challenges.

2) The study showed that the majority of respondents consider that the institutional methods of the organizational processes of public relations are the backbone of the institutional and organizational development in the short and long term.

3) The study showed that the organizational processes for public relations and its standards in developing institutional work within institutions are nothing but a kind of administrative development that includes internal job performance and proper planning. This means the beginning of a good work environment that uses the best management practices based on systematic scientific foundations, and studied scientific training and qualification. By enhancing their capabilities, their productivity and efficiency increased; Thus, its impact was reflected in directing institutional behavior.

4) The study showed that business practices based on organizational processes still suffer from a great weakness in terms of the quality of the programs provided. In addition to the limitations and scarcity of the offered programs, and the consequent deficiency in developing employee knowledge and skills, training plans and strategies are largely absent.

5) The study indicated that the effectiveness of organizational process methods in managing public relations has dealt with the most important part of the standards for developing institutional work in administrative processes as a new institutional direction to participate in decision-making as one of the pillars of institutional communication. And the main pillars in achieving positive interaction for the development of institutional work.

6) The study showed that developing the organizational structure of their institutions is what guarantees the activation of communication and communication channels within them and the participation of all in decision-making. Therefore, there is an effective role in achieving interaction within the institution.

7) The study proved that the institutional building mechanisms for the organizational processes used in public relations management in developing institutional work are due to good planning, and I mean here institutional planning. So that it includes setting training plans, developing cadres and administrative development plans in the institution itself, and well thought-out planning forms the core from which comprehensive construction processes are launched, and it is clearly noted that plans in institutions, if any, have not been reviewed, evaluated, and addressed their deficiencies.

8) The results indicated that the majority of respondents believe that there are mechanisms that helped the Public Relations Department to develop its institutional knowledge through the organizational processes used, and this is represented in the development of systems, structures and strategies that lead to appropriate employment and investment of human resources, as the percentage of those who strongly agree is (18.2). \%) Of the total sample of respondents, and a percentage (42.3\%). Of the sample respondents agree on the existence of mechanisms for organizational processes in solving problems a, and then enhancing their capabilities to deal with work requirements. However, there were impartial answers that did not clarify this with a percentage (8\%), while the percentage of non-conformists reached (26.9\%) for the lack of clear mechanisms for the organizational processes used in public relations in their organizations. There are clear mechanisms for the organizational processes used in public relations in their organizations.

\section{CONCLUSION}

Attention is required to organizational processes and practical of the development of institutional work because they are practical of renewable take into account in the development of the basic illusion - based workers or practitioners of public relations work within their organizations ; Where both complement the other.

The mechanisms of the organizational processes used and the standards for the development and return from the institutional work process must be reviewed .And that is through the organizational structures of the institutions and what is compatible with the employee's job tasks within the public relations of their institutions in which they work, considering that it has a significant impact on the conciliation of efforts, to evaluate the performance of the institutional work. In addition, attention must be paid to the comprehensive institutional building processes because it is the nucleus from which

the organizational processes used for public relations are based through review, evaluation and addressing the deficiencies of development

plans for institutional work that suffer from weaknesses and deficiencies due to the lack of specialized and qualified competencies to develop and evaluate those plans. The presence of another body that is concerned with continuous evaluation and accountability .Accordingly, it is imperative to introduce, specifications and standards for the organizational processes used for public relations as methods for managing the institution in accordance with a modern, clear corporate system that has its own identity and independent entity that achieves job satisfaction for workers in the institution, and the institutional career rotation that contributes significantly to the development of institutional work in light of the standards of their institutions and work To meet the challenges and make changes that seek to achieve its institutional interests in the short and long term . Despite the great development in the use of communication techniques in these institutions, attention must be paid to the use of communication methods and the use of modern technology as institutional technological methods that help in developing the institutional performance of the organizational processes used for public relations that facilitate organizational communication and communication processes about the use of these technologies in light of institutional standards.

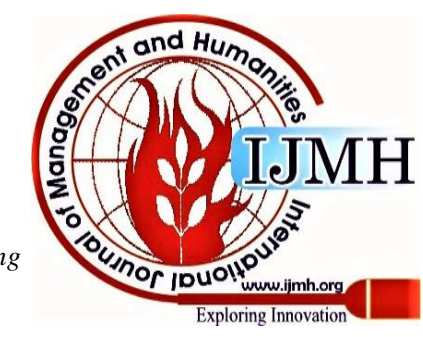




\section{Developing Institutional Work}

\section{REFERENCES}

1. Ahmed Abdullah Al-Sabab, Abdel-Hamid Diabo Khaled Maimani and Shakeel Ghulam, Fundamentals of Modern Management, (Jeddah: Khwarazm Al- Alamiya2013 ), p.(88-78)

2. Hussein Abdel-Hamid Ahmed Rashwan: Sociology of Organization, University Foundation, Alexandria, Egypt,2014 ,s 23.24

3. Hanna Qish, Abdel-Moati Assaf, Zuhair Al-Sabbagh and Mustafa Al-Shawish,

Organization and Institutional Methods ,Office Administration), Cai ro: United Arab Marketing and Supplies Company, 2018), 99-100.

4. Daphne Pan, Education in Singapore " the quality model" - education and the world of the Arab, (Abu Dhabi $\mathrm{J}$ :Emirates Center for Strategic Studies and Research, 2000), p.92,89

5. Sami Gamal El-Din, Administration and Administrative Organization) ,Alexandria: Horus International Publishing Foundation, 2014) pp..205-188

6. Saeed bin Ali Al-Adadhi, Al-Arabiya website ,Friday 20 ,Jumada Al-Thani 1433 AH - May 2012

7. Sinan Ghalib Almrhia, the life cycle Almasshuallagueth environment, structure and effectiveness of the organizational, RESALE of Ph.D. published, ,1996 p.29-24

8. Shadwan Ali Sheiba, Public Relations between Theory and Practice, (Cairo: University Knowledge House for Publishing, 2017) ,p.199

9. Amer Albu Salama, Society Magazine, March 2015, http://mugtama.com/articles/item/15997

10. Abdel Mohy Faleh, Mahmoud Saleh, Jalal El Din Abdel Khaleq and Mr. Ramadan, Public Relations and Media in Social Work, (Cairo : University Knowledge House, 2014), p. 24.

11. Essam Muhammad Al-Buhaisi, Modern Information Technology and its Impact on Administrative Decisions in Business Organizations ,2012 p.3-2

12. Ali Al-Sharkawy: Administrative Process, Directors' Jobs, New University Publishing House, Alexandria, Egypt, 6th floor. 2012M

13. Gharib Abdul Sami Gharib: Communication and Public Relations in Contemporary Society, University Youth Foundation, Alexandria,2014M

14. Fadil Dlao: Contact, concepts, theories, and its means, da t dawn for publication and distribution, Cairo1, $2013 \mathrm{M}$

15. Mohammad Akram Adlouni, institutional and enterprise life cycle, an article journalist, collection of January 14, 2011

16. Muhammad Akram Al-Adlouni, Institutional Work, (Beirut, Ibn Hazm House for Printing, Publishing and Distribution, 2012M

17. Muhammad Shaker Asfour: Origins of Organization and Methods, Dar Al-Masirah for Publishing, Distribution and Printing, Amman, ed3 ,2015

18. Mohammed Naji Ben Attia, the institutional structure of reality and the prospects for development ,study) field researcher carried out by charitable organizations in the Secretariat of the capital Sana'a, Republic of Yemen.2016

19. Muhammad Naji Gohar: Organizational Communication, University Book House, United Arab Emirates,2000

20. Moore, William L. And Harriet Moore, quality rings: changing impressions of individuals at work, translated by Zainal Abidin Abdul womb n Alhfeza, a review of Sami Ali Persian, (Riyadh :Institute of Public Administration, 2012

21. Hisham Al-Talib, The Human Development Index, ) Human Development Series, International Institute for Islamic Thought, 2010

22. Fligstein, N. 2011 'Institutional entrepreneurs and cultural frames: The case of the European Union's single market program'. European Societies 3/3:

23. Jepperson, RL 2014 'Institutions, institutional effects and institutionalism'. In The new institutionalism in organizational analysis, www Powell. and P. J DiMaggio (eds.), Chicago: The University of Chicago Press:

24. Long Loid, I, (2011), the anatomy of ethical leadership to lead our organization in conscientious and authentic manner.

25. Lounsbury, M. and Vent esca, M. 2013 'The new structuralism in organizational theory.' Organization, 10/3: pp 457-480

26. Scott, R. 2013 Institutions and organizations. Thousand Oaks, CA: Sage,

\section{AUTHORS PROFILE}

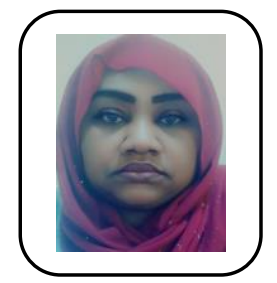

Dr. Maha Mustafa Omar Abdalaziz, Assistant Professor of Public Relations, College of Mass Communication and Public Relations, Fujairah University (UAE) She obtained a PhD in the field of public relations and advertising in the year 2012, and she has many papers published in the field of public relations, advertising and communication.

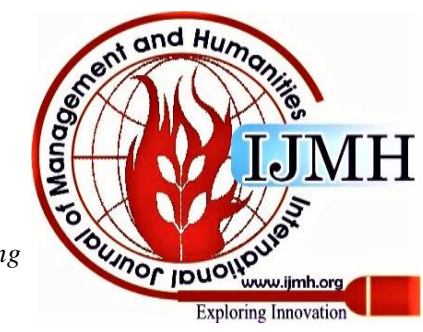

